\title{
EDITORIAL
}

\section{New managing editor}

\section{Rune Dahlqvist}

Professor Nicholas Bateman in Edinburgh has been active as managing editor for the EJCP for a number of years and his experience, his creativity, and his enthusiasm have been of great value to this Journal. Professor Nicholas Bateman is now taking on another major commission of trust and therefore has chosen to step down from the EJCP. From the Journal and from the colleagues working with the Journal, we want to extend our warmest thanks to Professor Nicholas Bateman for his excellent contributions.

We are lucky to have been able to recruit Dr David Williams, Department of Medicine and Therapeutics, University of Aberdeen, as a new managing editor. It is a pleasure to welcome Dr David Williams as an active collaborator with the European Journal of Clinical Pharmacology.

R. Dahlqvist $(\triangle)$

Klinisk Farmakologi, Umeå Universitet,

90187 Umeå, Sweden

e-mail: rune.dahlqvist@pharm.umu.se 